\title{
BMJ Open Intensity and duration of lifestyle interventions for long-term weight loss and association with mortality: a meta- analysis of randomised trials
}

Navneet Singh, ${ }^{\oplus 1}$ Ralph Alan Huston Stewart, ${ }^{2}$ Jocelyne Rachelle Benatar $^{\odot}$

To cite: Singh N, Stewart RAH, Benatar JR. Intensity and duration of lifestyle interventions for long-term weight loss and association with mortality: a meta-analysis of randomised trials. BMJ Open 2019;9:e029966. doi:10.1136/ bmjopen-2019-029966

- Prepublication history and additional material for this paper are available online. To view these files, please visit the journal online (http://dx.doi org/10.1136/bmjopen-2019029966).

Received 19 February 2019 Revised 21 July 2019 Accepted 23 July 2019

\section{Check for updates}

(c) Author(s) (or their employer(s)) 2019. Re-use permitted under CC BY-NC. No commercial re-use. See rights and permissions. Published by BMJ.

${ }^{1}$ School of Medicine, The University of Auckland, Auckland, New Zealand ${ }^{2}$ Green Lane Cardiovascular Service, Auckland City Hospital, Auckland, New Zealand

Correspondence to Dr Jocelyne Rachelle Benatar; jbenatar@adhb.govt.nz

\section{ABSTRACT}

Objectives To evaluate the importance of the frequency and duration of lifestyle interventions for achieving weight loss over $\geq 1$ year and associations with all-cause mortality. Design Meta-analysis of randomised trials using Preferred Reporting Items for Systematic Reviews and Meta-Analyses guidelines and RevMan software version $5 \cdot 2$ (The Nordic Cochrane Centre, The Cochrane Collaboration, Copenhagen).

Data sources MEDLINE, CENTRAL, Google and Science Direct databases alongside reference lists of appropriate articles and meta-analyses.

Eligibility criteria Randomised studies published in English-language journals from 1980 to June 2018 that assessed lifestyle compared with control interventions on weight loss and that included $\geq 100$ subjects and reported weight change and mortality for $\geq 1$ year.

Data extraction and synthesis Two independent reviewers extracted data and assessed risk of bias. Data were pooled using the generic inverse-variance method and expressed as mean differences (MDs) with $95 \% \mathrm{Cl}$ and $\mathrm{OR}$ with $95 \% \mathrm{Cl}$ as appropriate. Heterogeneity was assessed (Cochran Q statistic) and quantified $\left(I^{2}\right.$ statistic). The Grading of Recommendations Assessment, Development, and Evaluation score was used to assess the certainty of the evidence.

Results 31 randomised trials with a total of 20816 overweight or obese participants were included. $70 \%$ of participants had cardiometabolic risk factors. Body weight was lower for lifestyle intervention compared with the control at 1 year $(3.63 \mathrm{~kg}, 95 \% \mathrm{Cl} 2.58$ to 4.67$)$ and at 3 years $(2.45 \mathrm{~kg}, 95 \% \mathrm{Cl} 1.17$ to 3.73$)$. Weight loss at 1 year was greater in studies with $>28$ compared with $\leq 28$ interventions per year $(4.50 \mathrm{~kg}, 95 \% \mathrm{Cl} 3.03,5.97$ vs 2.38 , $95 \% \mathrm{Cl} 0.78$ to $3.98 \mathrm{~kg}, \mathrm{p}=0.001)$. In all studies, there were 593 deaths ( 0.3\%/year). The ORs for mortality for weight loss interventions compared with the controls was 0.86 (95\% Cl 0.73 to 1.02), $p=0.09$.

Conclusion In predominantly healthy populations with risk factors, there is a dose response with number of lifestyle interventions and weight loss. Frequent and sustained interventions are needed to achieve a clinically significant $5 \%$ weight loss. There was insufficient evidence to reliably evaluate the benefits in persons with known cardiovascular disease or cancer.

Trial registration number CRD42018095067.

\section{Strengths and limitations of this study}

- Previous meta-analyses of randomised trials of lifestyle interventions have not considered the level of intervention needed to achieve clinically meaningful $(>5 \%)$ weight loss. There was wide variation in the type of lifestyle advice, but it was not possible to assess which type of lifestyle advice is most effective.

- Most evidence is in middle-aged people (age 50-60 years) with cardiometabolic risk factors. There is limited data on effects of lifestyle interventions for weight loss in older patients and those with cardiovascular disease or cancer.

- Lifestyle interventions for weight loss may reduce mortality if sustained. However, in most studies, the duration of the intervention and follow-up was too short and mortality was too low to allow a reliable assessment.

\section{INTRODUCTION}

It has been estimated that nearly a third of the world's population are either obese (body mass index $(\mathrm{BMI}) \geq 30 \mathrm{~kg} / \mathrm{m}^{2}$ ) or overweight $\left(25 \leq \mathrm{BMI}<30 \mathrm{~kg} / \mathrm{m}^{2}\right) .{ }^{1}$ International guidelines in cardiology, ${ }^{2-4}$ diabetes ${ }^{5}$ and cancer ${ }^{7}$ recommend changing lifestyle-related factors for management of overweight and obesity. These lifestyle recommendations $^{2-4} 7-10$ are largely based on data from observational epidemiological studies in which obesity was associated with an increased risk of metabolic syndrome, diabetes, arthritis, heart disease and/or cancer. ${ }^{11-16}$ However, observational studies do not provide reliable information on whether lifestyle interventions should be recommended in obese people, and several relevant questions remained unanswered: do lifestyle interventions lead to weight reduction, if so, by how much, and is this maintained over time? What level of lifestyle intervention is needed, how long should these interventions be continued and do lifestyle interventions which target weight 


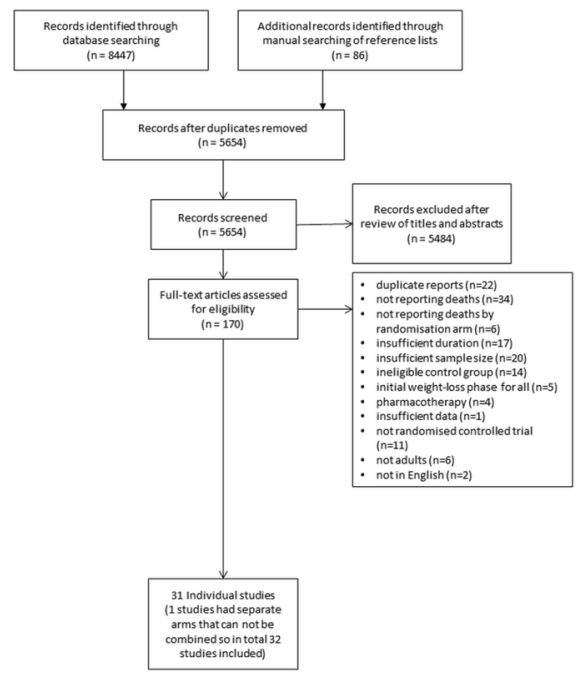

Figure 1 Study flow chart.

reduction improve health and lower the mortality risk? The aim of this meta-analysis was to determine whether published randomised trials of lifestyle interventions for weight loss provide evidence on whether the dose of lifestyle intervention influences the effectiveness of longer term weight reduction or mortality.

\section{METHODS}

Preferred Reporting Items for Systematic Reviews and Meta-Analyses guidelines on reporting systematic reviews and meta-analyses of studies were used throughout the planning, conduct and interpretation of this meta-analysis. A review protocol was designed and is available in the online supplementary text.

There was no patient or public involvement in this study

\section{Study search and inclusion criteria}

The full strategy is described in online supplementary document 1: the study protocol. Searches of MEDLINE, CENTRAL, Google and Science Direct databases alongside reference lists of appropriate articles and meta-analyses were performed for any reports on randomised clinical trials that assessed lifestyle intervention on weight loss published in English-language journals from 1980 to June 2018. Key words used in searches to identify studies included 'weight', 'lifestyle', 'hypocaloric', 'diet', 'mortality', 'coronary', 'heart' and 'cardiovascular'. Articles retrieved using this search string were then limited to trials including weight loss and non-weight loss arms, a trial duration (weight loss and maintenance phase) $\geq 12$ months and mortality data by intervention group.

Eligible studies were randomised control studies longer than 1 year with $\geq 100$ overweight and obese adults (BMI $\geq 25 \mathrm{~kg} / \mathrm{m}^{2}$ ) participants randomised to an intentional weight loss lifestyle intervention and had an appropriate control group. Studies were only included if the control group received normal care-which could include standard healthy lifestyle information-but had no specific advice to achieve weight loss. The intervention arm needed to have intent for weight loss, mainly through the promotion of a hypocaloric diet, and had to include $\geq 1$ face-to-face intervention. Participants could be healthy or have established cardiovascular disease (CVD). Studies were excluded if both groups were prescribed specific diets (such as high-protein diets and OPTIFAST), included pharmacotherapy or surgery for weight loss or if the intervention was 'self- help'. Studies with $>5 \%$ lost to follow-up were also excluded to reduce the risk of bias. ${ }^{17}$

For mortality, eligible studies were required to report mortality data explicitly either in the Consolidated Standards of Reporting Trials diagram, as an outcome measure or as an adverse event (studies reporting 'no adverse events' was taken to mean that no deaths occurred, but studies reporting 'no adverse events related to intervention' without specifying the nature of these adverse events were excluded). Studies also were required to present sufficient data in order for calculations of mean weight changes in kilograms.

The search of these electronic databases to obtain suitable studies was carried out by two reviewers (NS and JRB). Any queries arising around the suitability of a particular study for inclusion was resolved by discussion with all reviewers (NS, JRB and RAS). In some situations, multiple papers reporting on the same clinical trial were used if each individual paper did not provide all required data and qualitative information on the study. Methodological and appropriate quantitative data were extracted and compiled in an electronic database from all included studies on three separate occasions independently by two reviewers (NS and JRB).

Baseline data extracted included study sample size, mean age and BMI, duration of intervention and follow-up and percentage of women. Each study's intervention was also categorised into levels of intensity depending on the number and frequency of dietary interventions. An 'individual session' was defined as an intervention delivered one to one by a dietitian/lifestyle coach/physician. A 'face to face' intervention was delivered in person. 'Remote interventions' were those delivered by telephone, emails or web-based programs. In one study that reported two interventions, but used the same control group, the face-to-face intervention, which was more intensive compared with the remote intervention, was used in the meta-analysis. ${ }^{18}$

Follow-up data included mean weight or weight loss at each follow-up time after 1 year and all-cause mortality. If relevant data were not presented in a study, the corresponding study authors were contacted. Questions arising during data extraction were resolved by consensus between reviewers (NS, JRB and RAS). Outcome measures were weight loss achieved at 1, 2 and 3 years, weight loss achieved at the end of study and intensity of intervention required to achieve weight loss and mortality. Weight loss at 1 year was the primary outcome. If not reported, the first weight recorded after the first year was used. ${ }^{19-24}$ 


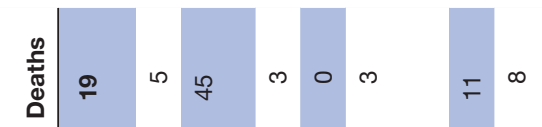

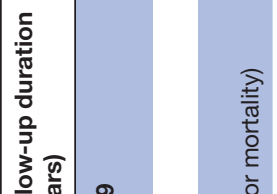

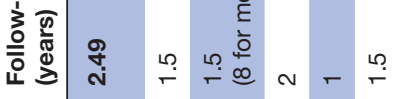

흘

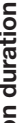

할

焉

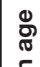

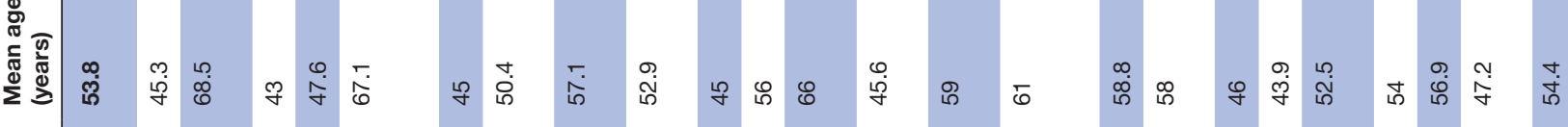

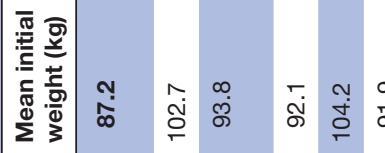

伭

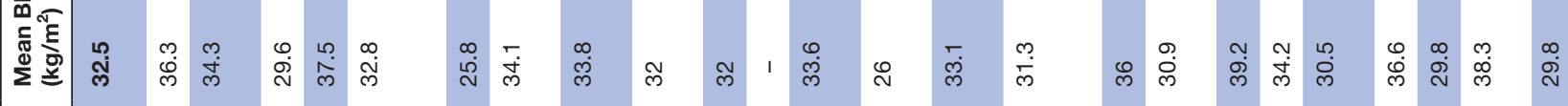

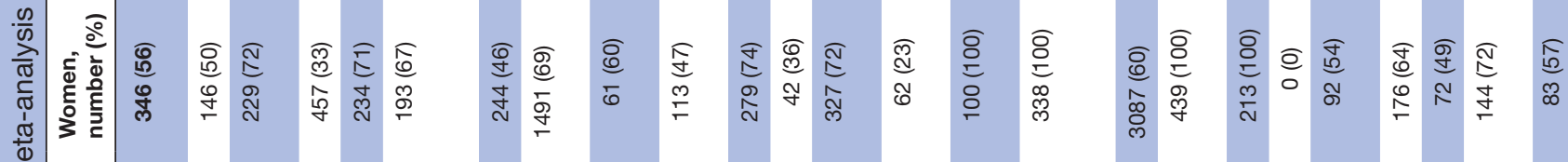

$\frac{10}{\frac{N}{N}}$

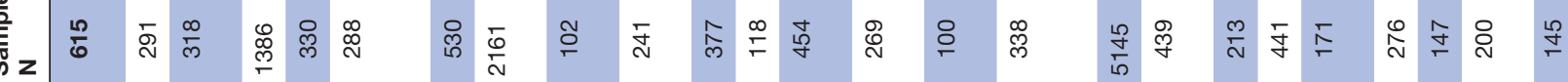
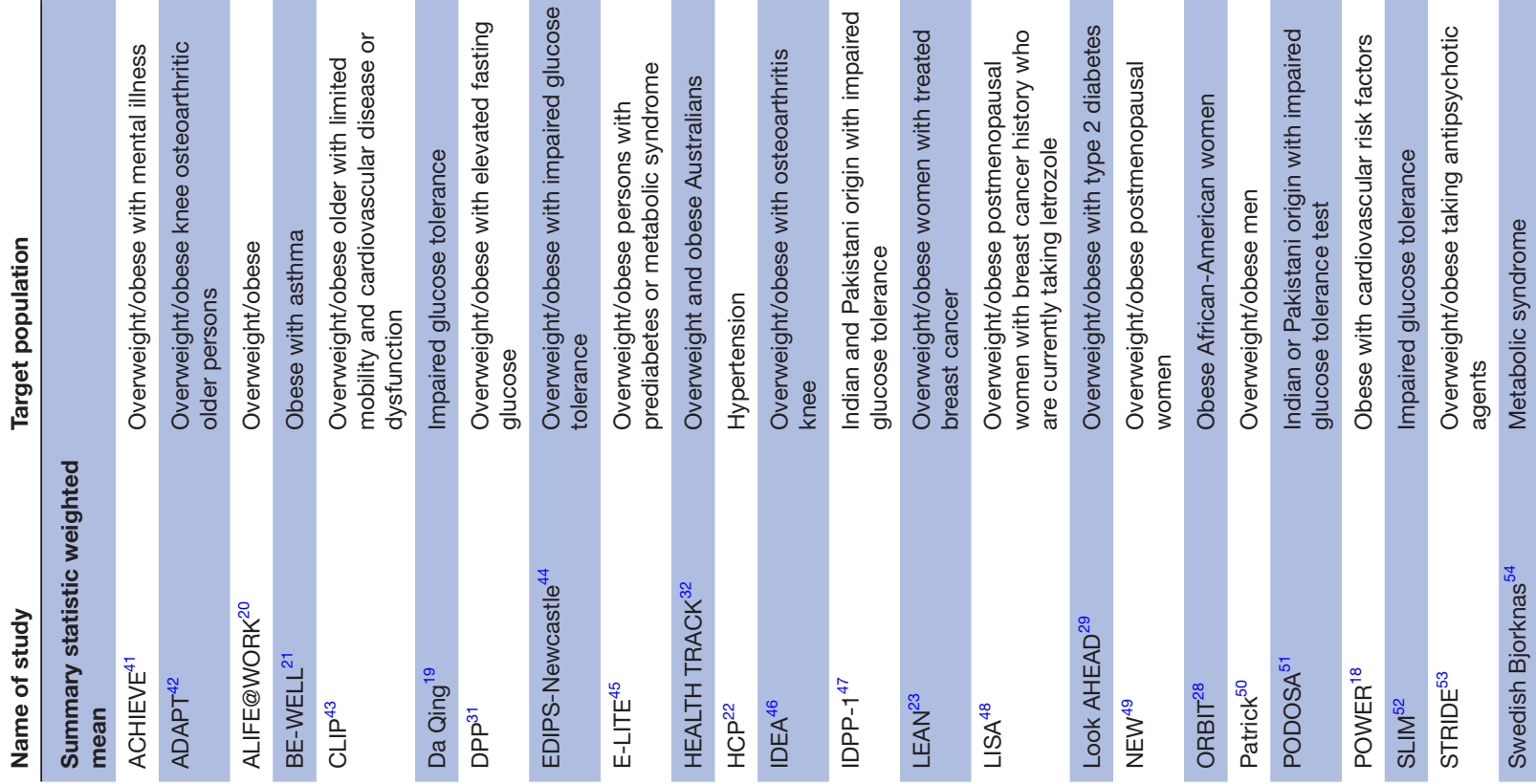

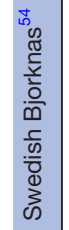




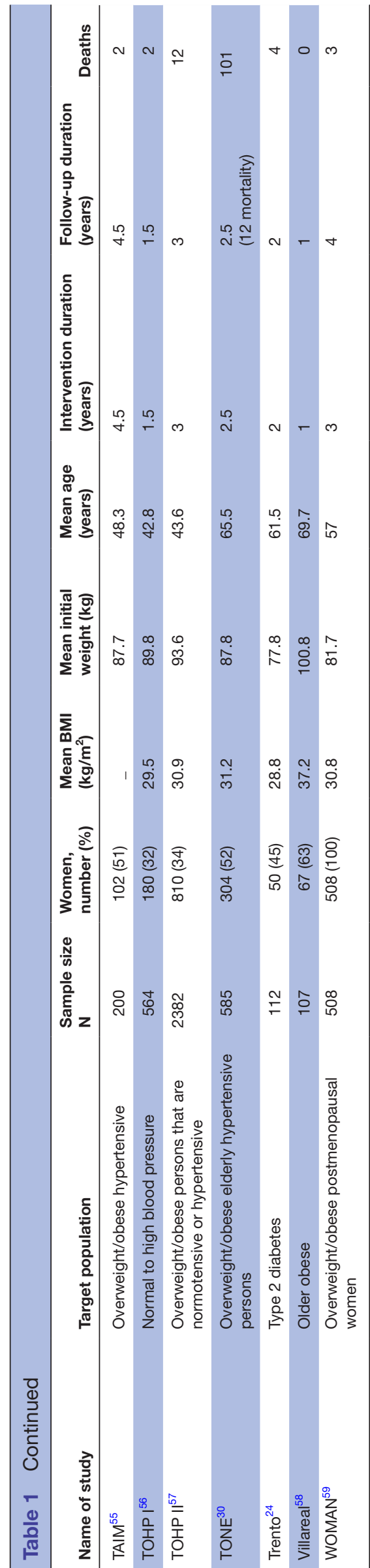

\section{Grading the evidence}

The Grading of Recommendations Assessment, Development, and Evaluation (GRADE) approach was used to assess the certainty of the evidence. ${ }^{25}$ Evidence was graded as high, moderate, low or very low quality. The included randomised controlled trials were graded as high-quality evidence by default and downgraded based on the following criteria: risk of bias, inconsistency, indirectness, imprecision and publication bias.

\section{Statistical analyses}

The inverse-variance method was used to pool mean differences for weight in kilograms and OR for mortality to yield an overall effect size with $95 \%$ CIs. For studies where SD or CIs were not available despite contacting authors, the mean SD for all other studies was used. SE or CIs were converted to SD using standard statistical formulae presented in the Cochrane Handbook for Systematic Reviews of Interventions 2011.

Each meta-analysis was assessed for heterogeneity by a $\chi^{2}$ test and $\mathrm{I}^{2}$ statistic. A fixed effects model was used when heterogeneity was not present $\left(\mathrm{I}^{2}<1 \%\right)$, and a random effects model was used when statistical heterogeneity $\left(\mathrm{I}^{2}\right.$ $\geq 1 \%$ ) was present. The meta-analysis was also repeated using a fixed effects model to assess the effects of small studies on results. ${ }^{26} \mathrm{~A} p$ value of $<0.05$ was considered statistically significant. Studies are presented in Forest plots in order of statistical power. A weighted average for weight loss per interventions was calculated.

For weight loss at 1-year and all-cause mortality, analysis was stratified by the mean baseline BMI, the median number of interventions $(\leq 28 ;>28$ interventions) and whether intentions were frontloaded $(<$ or $\geq 75 \%$ interventions in first 6 months). For weight loss over the length of follow-up, subgroup analysis was done for mean study BMI (25-29, 30-35 and >35), age (40-49, 50-60 and $\geq 60$ years) and number of interventions per year $(\leq 6,7-12$, $13-24$ and $\geq 25$ ).

Sensitivity analysis was undertaken to assess effects of studies that deviated significantly from the SE of the total study result or studies where baseline values differed significantly from the mean baseline. Funnel plots were used to assess for publication bias.

The statistical analyses were performed using RevMan software version 5.2 (The Nordic Cochrane Centre, The Cochrane Collaboration, Copenhagen). Subgroup analysis followed guidelines suggested by Wang. ${ }^{27}$

A regression analysis evaluated the relationship between the number of interventions/study and weight loss using Statistical Analysis System (SAS) software version 9.4 (SASInstitute Inc., Cary, NC, USA). Intervention doses more than $3 \mathrm{SD}$ above the mean were considered outliers and were removed from the analysis. ${ }^{28}$

\section{RESULTS}

From a review of 5654 titles and abstracts, 31 randomised trials with a total of 20563 participants met inclusion criteria. The most common reasons for excluding studies were 
Table 2 Frequency and mode of contact of lifestyle intervention

\begin{tabular}{|c|c|c|c|c|c|}
\hline Study name & Type of contact & Mode of contact & $\begin{array}{l}\text { Number of dietary } \\
\text { interventions in } \\
\text { year } 1\end{array}$ & $\begin{array}{l}\text { Number } \\
\text { of dietary } \\
\text { interventions in } \\
\text { year } 2\end{array}$ & $\begin{array}{l}\text { Proportion } \\
\text { of first year } \\
\text { interventions } \\
\text { in first } 6 \\
\text { months (\%) }\end{array}$ \\
\hline All studies & $\begin{array}{l}\text { Individual=7 } \\
\text { Group only=5 } \\
\text { Group+individual=19 }\end{array}$ & $\begin{array}{l}\text { Face to face }=11 \\
\text { Remote }=3 \\
\text { Face to } \\
\text { face+remote }=17\end{array}$ & 27.5 & 3.96 & 66 \\
\hline ACHIEVE $^{41}$ & $\mathrm{G}, \mathrm{I}$ & $\mathrm{F}$ & 30 & $x$ & 80 \\
\hline $\mathrm{ADAPT}^{42}$ & $\mathrm{G}, \mathrm{I}$ & $\mathrm{F}, \mathrm{R}$ & 33 & $x$ & 64 \\
\hline ALIFE@WORK ${ }^{20}$ & I & $\mathrm{R}$ & 10 & 0 & 100 \\
\hline BE-WELL ${ }^{21}$ & $\mathrm{G}, \mathrm{I}$ & $\mathrm{F}, \mathrm{R}$ & 18 & $x$ & 83 \\
\hline CLIP ${ }^{43}$ & $\mathrm{G}, \mathrm{I}$ & $\mathrm{F}, \mathrm{R}$ & 36 & $x$ & 67 \\
\hline Da Qing ${ }^{19}$ & $\mathrm{G}, \mathrm{I}$ & $\mathrm{F}$ & 16 & 4 & 80 \\
\hline $\mathrm{DPP}^{31}$ & $\mathrm{G}, \mathrm{I}$ & $\mathrm{F}, \mathrm{R}$ & 22 & 12 & 73 \\
\hline EDIPS-Newcastle ${ }^{44}$ & $\mathrm{G}, \mathrm{I}$ & $\mathrm{F}$ & 8 & $x$ & 75 \\
\hline E-LITE ${ }^{45}$ & $\mathrm{G}, \mathrm{I}$ & $\mathrm{F}, \mathrm{R}$ & 38 & $x$ & 61 \\
\hline HEALTH TRACK ${ }^{32}$ & I & $\mathrm{F}, \mathrm{R}$ & 6 & 6 & 50 \\
\hline $\mathrm{HCP}^{22}$ & I & $\mathrm{F}$ & 12 & 4 & 75 \\
\hline IDEA $^{46}$ & G,I & $\mathrm{F}, \mathrm{R}$ & 39 & $x$ & 62 \\
\hline IDPP $-1^{47}$ & I & $\mathrm{F}, \mathrm{R}$ & 15 & 14 & 53 \\
\hline LEAN $^{23}$ & I & $\mathrm{F}, \mathrm{R}$ & 11 & $x$ & 100 \\
\hline LISA $^{48}$ & I & $\mathrm{R}$ & 31 & 4 & 87 \\
\hline Look AHEAD ${ }^{29}$ & G,I & $\mathrm{F}, \mathrm{R}$ & 42 & 24 & 57 \\
\hline $\mathrm{NEW}^{49}$ & $\mathrm{G}, \mathrm{I}$ & $\mathrm{F}, \mathrm{R}$ & 32 & $x$ & 63 \\
\hline $\mathrm{ORBIT}^{28}$ & G,I & $\mathrm{F}, \mathrm{R}$ & 110 & $x$ & 56 \\
\hline Patrick $^{50}$ & I & $\mathrm{R}$ & 52 & $x$ & 50 \\
\hline PODOSA ${ }^{51}$ & G & $\mathrm{F}$ & 7 & 4 & 71 \\
\hline POWER $^{18}$ & G,I & $\mathrm{F}$ & 39 & 18 & 77 \\
\hline SLIM $^{52}$ & $\mathrm{G}, \mathrm{I}$ & $\mathrm{F}, \mathrm{R}$ & 5 & 4 & 60 \\
\hline STRIDE $^{53}$ & $\mathrm{G}, \mathrm{I}$ & $\mathrm{F}, \mathrm{R}$ & 36 & $x$ & 67 \\
\hline Swedish Bjorknas ${ }^{54}$ & G & $\mathrm{F}$ & 12 & 5 & 58 \\
\hline TAIM $^{55}$ & $\mathrm{G}, \mathrm{I}$ & $\mathrm{F}$ & 17 & 8 & 71 \\
\hline TOHP I $^{56}$ & G,I & $\mathrm{F}, \mathrm{R}$ & 26 & $x$ & 77 \\
\hline TOHP $\|^{57}$ & $\mathrm{G}, \mathrm{I}$ & $\mathrm{F}, \mathrm{R}$ & 28 & $x$ & 68 \\
\hline TONE $^{30}$ & $\mathrm{G}, \mathrm{I}$ & $\mathrm{F}$ & 28 & 12 & 71 \\
\hline Trento ${ }^{24}$ & $\mathrm{G}$ & $\mathrm{F}$ & 4 & 4 & 50 \\
\hline Villareal $^{58}$ & G & $\mathrm{F}$ & 52 & $x$ & 50 \\
\hline WOMAN ${ }^{59}$ & $\mathrm{G}$ & $\mathrm{F}$ & 40 & 12 & 50 \\
\hline
\end{tabular}

The type of contact refers to whether trial participants received individual (I) or group (G), and mode of contact outlines whether participants received interventions remotely by internet, email or over the phone $(R)$ or face to face $(F)$.

duplicate reports, sample size $<100$, duration of follow-up $<1$ year and no reporting of mortality (figure 1 ). In one study, there was a factorial design where a control group was compared with diet alone and exercise compared with exercise and diet. ${ }^{18}$ These two comparisons are reported separately for a total of 32 studies. Seventy per centof study participants had cardiometabolic risk factors. No study was found in patients with established CVD, although 14\% of participants in the Look AHEAD trial had cardiac disease. ${ }^{29}$

Included studies are summarised in table 1 . Most studies were small and only four studies had sample sizes $>1000$ in each arm. ${ }^{29-32}$ One study reported outcomes and weight 


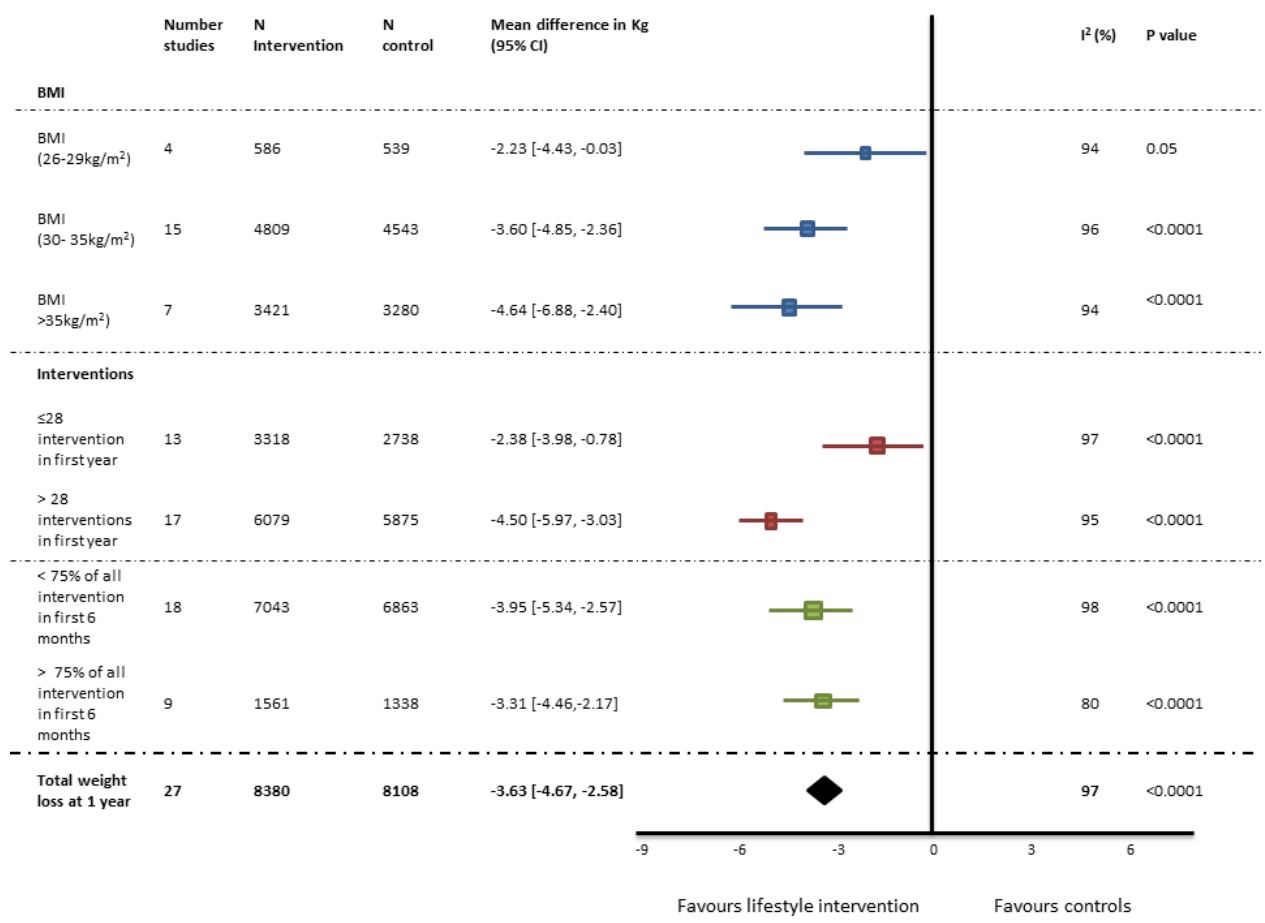

Figure 2 Effects of lifestyle intervention on weight loss at 1 year. BMI, body mass index.

only at 6 years, and this study is included only in the mortality analysis. ${ }^{19}$ The Da Qing study ${ }^{19}$ did not report summary measures of weight loss by randomised group, so also could only be included in mortality analysis. The Look AHEAD trial ${ }^{29}$ was both the largest study and had the longest follow-up. The GRADE scores for both the weight loss and mortality metaanalysis were high.

\section{Lifestyle interventions evaluated}

As described in table 2, there were large variations in types (individual or group), mode of (face to face or remote), timing and frequency of interventions between studies. In some studies, the number of interventions provided was dependent on an individual study participant's response to the weight loss programme, so it was not possible to accurately describe the dose of intervention for every study. For these studies, the average number of interventions was extrapolated based on the assumption that there was a normal distribution of extra interventions within the study.

The median number of interventions during the first year was 28 (IQR 12-37). In most studies, there were more interventions during the first 6 months, median 18 (IQR 10-24) interventions. Fourteen studies reported intervention beyond 1 year, and for these, the median number of interventions in year 2 was 5 (IQR 4-12). Few studies reported weight outcomes beyond 3 years.

\section{Effect of lifestyle interventions on body weight}

For all studies, the average weight loss per lifestyle intervention session at 1 year compared with controls was $0.13 \mathrm{~kg}$ (95\% CI 0.19 to 0.07 ). Effects on body weight are shown in figure 2 , table 3 and supplemental figures in online supplementary document 2 . Twenty-seven of the included studies reported weight loss at 1 year, 12 at 2 years and 8 at 3 years. For studies that did not report weight loss at 1 year, the first reported weight after 1 year was used to assess the relationship with median number of interventions and total weight loss. ${ }^{20224}$

Weight loss was greater in the intervention group compared with the control group $(3.63 \mathrm{~kg}, 95 \%$ CI 2.58 to 4.67 at 1 year. This difference decreased over time and at year 3 was $2.45 \mathrm{~kg}$ (95\% CI 1.17 to 3.73$)$. Funnel plots do not suggest publication bias.

Weight loss for studies with more than the median of 28 interventions/year was $4.50 \mathrm{~kg}$ (95\% CI 3.03 to 5.97 ), and $\leq 28$ interventions/year was $2.38 \mathrm{~kg}$ (95\% CI 0.78 to $3.98), p=0.001$. Weight loss is presented by the number of interventions/study in table 3. The estimated difference in weight loss between studies using the regression model was $0.6 \mathrm{~kg}$ (95\% CI 0.23 to 1.4) for each additional 10 interventions.

\section{Effects of lifestyle intervention on mortality}

Effects on mortality are presented in figure 3, Table 3 and online supplementary document 2 . In eight studies, there were no deaths during follow-up. For all studies combined, there were 593 deaths, during a weighted average follow-up of 9.2 years, equivalent to an average mortality rate of $0.3 \% /$ year. Mortality was non-significantly lower in the intervention compared with the control group, ORs 0.86 (95\% CI 0.73 to 1.02), $\mathrm{p}=0.09$. The number of interventions in the first year and weight loss achieved in the first year were not associated with mortality (table 3 ). There were too few deaths to confidently evaluate possible differences in the relationship between study characteristics and mortality (table 3 ). 
Table 3 Association with intervention intensity with weight loss achieved and mortality

\begin{tabular}{|c|c|c|c|c|c|c|c|}
\hline Characteristic & \multicolumn{3}{|c|}{$\begin{array}{l}\text { Weight loss } \\
\text { (from baseline and final reported)* }\end{array}$} & \multicolumn{4}{|l|}{ Mortality } \\
\hline \multicolumn{8}{|l|}{ Number of interventions per year } \\
\hline$\leq 6$ & 3 & $9 \%$ & 0.84 (0.28 to 1.40$)$ & 3 & $1 \%$ & $5 / 510(1.0 \%)$ & 1.45 (0.22 to 9.40$)$ \\
\hline $7-12$ & 6 & $17 \%$ & 2.04 (0.84 to 3.24$)$ & 6 & $2 \%$ & 10/2022 (0.5\%) & 1.34 (0.35 to 5.16$)$ \\
\hline$\geq 25$ & 17 & $60 \%$ & $3.53(2.92$ to 4.13$)$ & 17 & $93 \%$ & $555 / 13578(4.1 \%)$ & 0.84 (0.71 to 1.00$)$ \\
\hline \multicolumn{8}{|l|}{ BMI¥ } \\
\hline $25-29$ & 6 & $19 \%$ & $1.37(-0.09$ to 2.82$)$ & 8 & $11 \%$ & 23/3890 (0.6\%) & 1.58 (0.64 to 3.90$)$ \\
\hline $30-35$ & 16 & $48 \%$ & 3.09 (2.11 to 4.06$)$ & 14 & $22 \%$ & 136/8374 (1.6\%) & $0.93(0.65$ to 1.33$)$ \\
\hline$>35$ & 6 & $23 \%$ & 4.04 (2.47 to 5.61$)$ & 6 & $67 \%$ & $384 / 6370(6 \%)$ & 0.86 (0.69 to 1.05$)$ \\
\hline Healthy population & 8 & $29 \%$ & 3.03 (1.53 to 4.52$)$ & 8 & $3 \%$ & $12 / 3458(0.3 \%)$ & $1.23(0.39$ to 3.89$)$ \\
\hline $\begin{array}{l}\text { Other (arthritis, asthma and } \\
\text { mental illness) }\end{array}$ & 4 & $9 \%$ & 3.35 (2.18 to 4.52$)$ & 4 & $2 \%$ & $7 / 1275(0.6 \%)$ & $0.74(0.16$ to 3.37$)$ \\
\hline Cancer & 2 & $6 \%$ & 2.70 (1.57 to 3.83$)$ & 2 & $6 \%$ & $2 / 438(0.5 \%)$ & 0.98 (0.06 to 15.74$)$ \\
\hline \multicolumn{8}{|l|}{ Age (years) } \\
\hline $40-49$ & 12 & $47 \%$ & 2.29 (0.97 to 3.61$)$ & 14 & $9 \%$ & 50/9868 (0.5\%) & 1.28 (0.71 to 2.30$)$ \\
\hline $50-59$ & 12 & $39 \%$ & 3.27 (2.38 to 4.15$)$ & 12 & $69 \%$ & 396/9691 (3.8\%) & 0.84 (0.69 to 1.04$)$ \\
\hline$>60$ & 7 & $14 \%$ & 4.50 (2.76 to 6.25$)$ & 7 & $22 \%$ & 155/2202 (7.0\%) & $0.78(0.55$ to 1.10$)$ \\
\hline Look AHEAD & 1 & $4 \%$ & 3.40 (3.30 to 3.50$)$ & 1 & $65 \%$ & $376 / 5145$ (7.3\%) & 0.85 (0.69 to 1.05$)$ \\
\hline All other studies & 29 & $96 \%$ & 3.01 (2.23 to 3.79 ) & 32 & $35 \%$ & 207/14455 (1.4\%) & $0.88(0.66$ to 1.17$)$ \\
\hline
\end{tabular}

${ }^{*} \mathrm{P}<0.0001$ for all.

†Da Quing excluded for all weight loss.

$\ddagger \mathrm{TAIM}^{55}$ and $\mathrm{HCP}^{22}$ excluded for BMI.

$\mathrm{BMI}$, body mass index.

\section{Importance of the Look AHEAD trial}

The Look AHEAD trial ${ }^{29}$ contributed $25 \%$ of people to the meta-analysis and accounted for $63 \%$ of deaths. This trial randomised 5145 overweight or obese patients with type 2 diabetes, $14 \%$ also had established heart disease, $60 \%$ were women and the mean age was 59 years. The lifestyle intervention included weekly face-to-face meetings for the first 6 months, meetings three times a month for the next 6 months and then monthly until the end of study. Patients were followed for median 9.6 years (IQR 8.9 to 10.3$)$. A clinically meaningful $5 \%-10 \%$ weight loss was achieved. The HR for all-cause mortality was $0.85(95 \%$

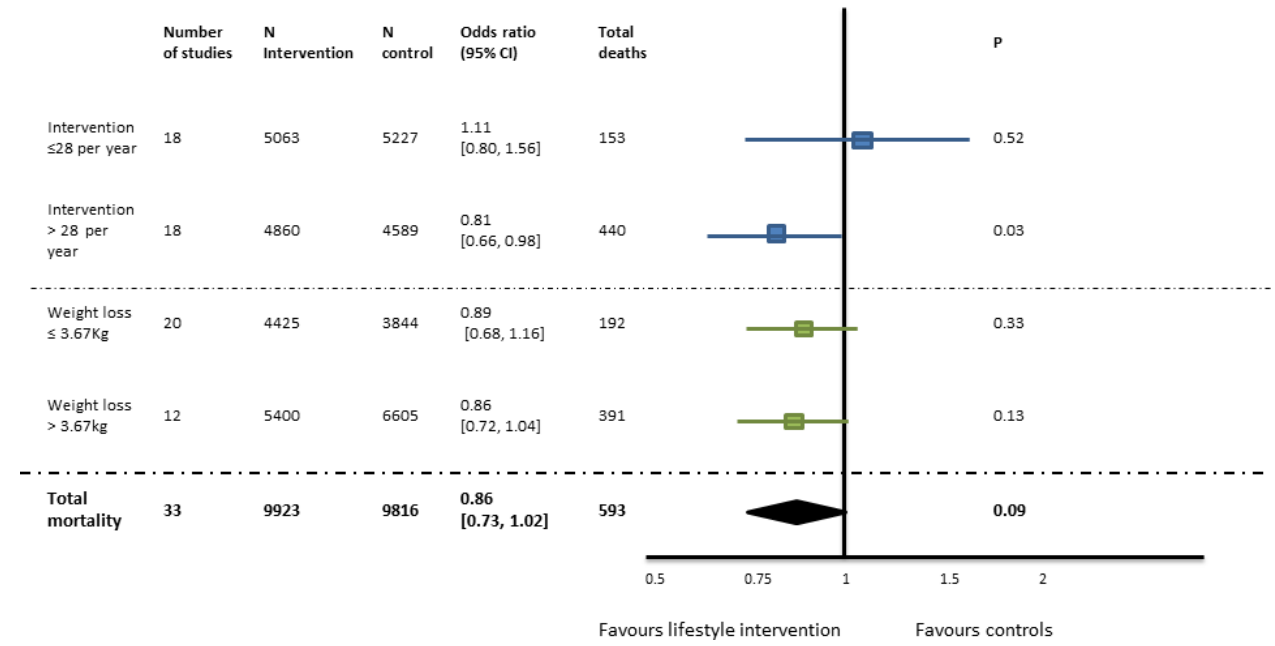

Figure 3 Effects of weight loss on mortality during a weighted average follow-up of 9.2 years. There is no heterogeneity for all $\left(I^{2}=0\right)$. 
CI 0.69 to $1.04 ; \mathrm{p}=0.11$ ). Estimated effects on mortality and body weight in the Look AHEAD trial ${ }^{29}$ were similar to those observed in all other studies combined (table 3).

\section{DISCUSSION}

There are four important conclusions from this meta-analysis (box 1). First, most studies were conducted in people aged 50-60 years with cardiometabolic risk factors (table 3). There were few studies in the elderly or in those with established cardiovascular or other diseases. Second lifestyle interventions compared with 'usual' care result in a modest reduction in body weight, on average $3.63 \mathrm{~kg}$ at 1 year, with about $2 / 3$ of this sustained after $2-3$ years. Weight loss was slightly greater in very obese and obese persons compared with overweight but was still on average $<5 \%$ of body weight for all groups. Third, there was probably a dose response with greater weight loss with more frequent lifestyle interventions. Clinically meaningful $>5 \%$ weight loss, as defined by the American College of Cardiology/American Heart Association Task Force on Practice Guidelines and The Obesity Society, ${ }^{33}$ was achieved with $>28$ interventions over 1 year but not for shorter interventions. Fourth, lifestyle interventions were associated with a modest reduction in all-cause mortality (point estimate $\sim 14 \%$ ) but with wide CIs. This estimate is similar to a previous meta-analyses that reported that lifestyle interventions decreased all-cause mortality (Relative risk $(\mathrm{RR})=0.85 ; 95 \% \mathrm{CI} 0.73$ to 1.00 and $0.82,95 \%$ CI 0.71 to 0.95$),{ }^{3435}$ but these meta-analyses did not evaluate the importance of the intensity and duration of the lifestyle interventions.

In most studies there was a substantial effort for the lifestyle intervention group, with a median of 28 interventions over the first year. Comparison across studies suggests more interventions were associated with greater weight loss at 1 year, but no studies directly compared different intervention intensities or durations. There was limited data on the efficacy of shorter lifestyle interventions or whether simple lifestyle advice from a health practitioner is effective. Most studies included relatively small numbers of participants, and lifestyle interventions varied markedly. It was not possible to confidently evaluate the impact of different types of lifestyle advice or the

\section{Box 1 Key message box}

- An average 28 interventions (more than twice a month) in the first year achieved $3.63 \mathrm{~kg}$ weight loss at 1 year. Interventions included seeing doctors, nurses, dieticians, nutritionist and psychologists.

- Evidence that weight loss reduces mortality is from large, long-term studies with frequent interventions in middle aged patients with cardiometabolic risk factors.

- The effectiveness of simple lifestyle advice by medical practitioners or a limited number of interventions to achieve sustained weight loss is uncertain. relative strengths of face-to-face compared with remote interventions.

This analysis provides insights on why obtaining reliable information on the impact of lifestyle interventions on mortality is so difficult. The meta-analysis included randomised data from over 20000 patients with $\sim 190000$ patient-years of follow-up. However, the mortality rate was only $0.3 \%$ / year, and only three studies ${ }^{29} 30$ reported more than 10 deaths. There were also too few deaths in studies with fewer interventions, in healthy populations and in people younger than 50 years to reliably evaluate the effects in these groups. Modest mortality benefits of sustained weight reduction may be expected to occur during longer follow-up. In the Look AHEAD trial, ${ }^{29}$ which followed patients for nearly 10 years, the $14 \%$ reduction in all-cause mortality was similar to all other studies combined, supporting the conclusion that this mortality reduction is real. Although of borderline statistical significance, this modest mortality benefit is consistent with observational studies that report that bariatric surgery is associated with lower all-cause, cardiovascular and cancer-related mortality. ${ }^{37}$ However, compared with lifestyle interventions, bariatric surgery results in much larger and sustained reductions in body weight. ${ }^{38}$

Findings from this study are relevant to clinical practice guidelines on interventions for weight loss. Although lifestyle interventions are associated with lower body weight and a probable small reduction in mortality, there is only reliable evidence for very comprehensive programmes that include many interactions sustained over months. There is limited evidence that shorter and simpler interventions, more typical of usual clinical practice, have a clinically meaningful benefit. ${ }^{39}$ Also, we were unable to evaluate whether weight loss is maintained after cessation of the lifestyle intervention, because most studies did not report outcomes after the intervention stops. The efficacy of lifestyle programmes in the 'real word' is likely to be less than for volunteers in clinical trials who are generally highly motivated. These observations are important to inform realistic expectations on weight loss with lifestyle interventions, which may be much less than 'expected' by many clinicians and patients.

\section{Study limitations}

Individual participant data were not available, and this limits the ability to address several important questions. It is possible some individuals lose significant weight, while others lose none, but this could not be reliably evaluated from summary data. It was also not possible to evaluate the benefit of weight loss in subgroups of individuals who lost the most weight. It is not clear the degree to which weight loss is dependent on individual participant characteristics such as BMI, gender, age and ethnicity. Most studies did not provide information on food consumed or exercise performed, and it was not possible to assess adherence to randomised treatments or to compare different types of lifestyle intervention. It was not possible to compare the nature of the interventions and type of 
lifestyle advice given. Intensive lifestyle interventions have been reported to reduce progression of diabetes and to be cost-effective. ${ }^{40}$ The current meta-analysis did not assess other potential health benefits of weight loss such as reducing progression to diabetes.

\section{CONCLUSION}

Lifestyle programmes with frequent patient interactions sustained over a year or more can achieve clinically meaningful weight loss, and this may lower mortality during long term follow-up. However, the benefits of less frequent interventions over shorter durations in body weight are more modest, and long-term benefits to mortality risk are uncertain. Because there is limited data from randomised trials, it is uncertain whether lifestyle interventions for obesity decrease mortality in persons with cancer, heart failure or ischaemic heart disease.

Contributors All authors: conception of study, adjudication inclusion of studies and draft version manuscript. NS and JRB: electronic database searches, data extraction and performed the analysis. RAHS and JRB wrote the subsequent and final versions of manuscript in consultation with NS. JRB: performed futher statistical analysis (regression model) and designed the figures and tables. All authors discussed the results and commented on the manuscript.

Funding The authors have not declared a specific grant for this research from any funding agency in the public, commercial or not-for-profit sectors.

Competing interests None declared.

Patient consent for publication Not required.

Provenance and peer review Not commissioned; externally peer reviewed.

Data availability statement All data relevant to the study are included in the article or uploaded as supplementary information.

Open access This is an open access article distributed in accordance with the Creative Commons Attribution Non Commercial (CC BY-NC 4.0) license, which permits others to distribute, remix, adapt, build upon this work non-commercially, and license their derivative works on different terms, provided the original work is properly cited, appropriate credit is given, any changes made indicated, and the use is non-commercial. See: http://creativecommons.org/licenses/by-nc/4.0/.

\section{REFERENCES}

1. Organisation WH. Obesity and overweight: World health Organisation [updated Feb 2018; cited 27 Mar 2018], 2018. Available: http://www. who.int/mediacentre/factsheets/fs311/en/

2. Piepoli MF, Corrà U, Adamopoulos $\mathrm{S}$, et al. Secondary prevention in the clinical management of patients with cardiovascular diseases. Core components, standards and outcome measures for referral and delivery: a policy statement from the cardiac rehabilitation section of the European Association for Cardiovascular Prevention \& Rehabilitation. Endorsed by the Committee for Practice Guidelines of the European Society of Cardiology. Eur J Prev Cardiol 2014;21:664-81.

3. Amsterdam EA, Wenger NK, Brindis RG, et al. 2014 AHA/ACC guideline for the management of patients with non-ST-elevation acute coronary syndromes: Executive summary: a report of the American College of Cardiology/American heart association Task force on practice guidelines. Circulation 2014;130:2354-94.

4. Montalescot G, Sechtem U, Achenbach S, et al. 2013 ESC guidelines on the management of stable coronary artery disease: the task force on the management of stable coronary artery disease of the European Society of cardiology. Eur Heart J 2013;34:2949-3003.

5. International Diabetes Federation. International Diabetes Federation Diabetes Atlas Brussels, Belgium [updated 17 August 2013; cited 201413 July 2014]. 5th edn, 2011. Available: http://www.idf.org/ diabetesatlas

6. Sonne DP, Hemmingsen B. Comment on American Diabetes Association. Standards of Medical Care in Diabetes-2017. Diabetes Care 2017;40(Suppl. 1):S1-S135. Diabetes Care 2017;40:e92-3.
7. Society AC. ACS Guidelines for Nutrition and Physical Activity [updated 13 Apr 2017; cited 12 Apr 2018], 2017. Available: https:// www.cancer.org/healthy/eat-healthy-get-active/acs-guidelinesnutrition-physical-activity-cancer-prevention/guidelines.html

8. 2015-2020 Dietary Guidelines for Americans. United States of America: USDA center for nutrition policy and promotion. (ODPHP) OoDPaHP, 2015

9. European Dietary Guidelines. European Dietary Guidelines [cited 28 Nov 2012]. Available: http://www.eufic.org/article/en/expid/foodbased-dietary-guidelines-in-europe/

10. DeSalvo KB. Public health 3.0: applying the 2015-2020 dietary guidelines for Americans. Public Health Rep 2016;131:518-21.

11. Lyall DM, Celis-Morales $\mathrm{C}$, Ward $\mathrm{J}$, et al. Association of body mass index with cardiometabolic disease in the UK Biobank: a Mendelian randomization study. JAMA Cardiol 2017;2:882-9.

12. Chang VW, Langa KM, Weir D, et al. The obesity paradox and incident cardiovascular disease: a population-based study. PLOS One 2017;12:e0188636.

13. Richardson A, Hayes J, Frampton C, et al. Modifiable lifestyle factors that could reduce the incidence of colorectal cancer in New Zealand. N Z Med J 2016;129:13-20.

14. Tee MC, Cao Y, Warnock GL, et al. Effect of bariatric surgery on oncologic outcomes: a systematic review and meta-analysis. Surg Endosc 2013;27:4449-56.

15. Flint AJ, Rexrode KM, Hu FB, et al. Body mass index, waist circumference, and risk of coronary heart disease: a prospective study among men and women. Obes Res Clin Pract 2010;4:e171-81.

16. Low S, Chin MC, Deurenberg-Yap M. Review on epidemic of obesity. Ann Acad Med Singapore 2009;38:57-9.

17. Henderson AR. Evidence-Based Medicine. How to Practice and Teach EBM, 2nd ed. David L. Sackett, Sharon E. Straus, W. Scott Richardson, William Rosenberg, and R. Brian Haynes. Edinburgh: Churchill Livingstone, 2000, 261 pp. (plus one compact disc), \$34.95. ISBN 0-443-06240-4. Clinical Chemistry 1997;43:2014.

18. Appel LJ, Clark JM, Yeh H-C, et al. Comparative effectiveness of weight-loss interventions in clinical practice. N Engl J Med 2011;365:1959-68.

19. Pan XR, Li GW, Hu YH, et al. Effects of diet and exercise in preventing NIDDM in people with impaired glucose tolerance. The dA Qing IGT and diabetes study. Diabetes Care 1997;20:537-44.

20. van Wier MF, Dekkers JC, Hendriksen IJM, et al. Effectiveness of phone and e-mail lifestyle counseling for long term weight control among overweight employees. J Occup Environ Med 2011;53:680-6.

21. Ma J, Strub P, Xiao L, et al. Behavioral weight loss and physical activity intervention in obese adults with asthma. A randomized trial. Ann Am Thorac Soc 2015;12:1-11.

22. Stamler R, Stamler J, Grimm R, et al. Nutritional therapy for high blood pressure. Final report of a four-year randomized controlled trial-the Hypertension Control Program. JAMA 1987;257:1484-91.

23. Harrigan M, Cartmel B, Loftfield E, et al. Randomized trial comparing telephone versus In-Person weight loss counseling on body composition and circulating biomarkers in women treated for breast cancer: the lifestyle, exercise, and nutrition (lean) study. J Clin Oncol 2016;34:669-76

24. Trento M, Passera P, Tomalino M, et al. Group visits improve metabolic control in type 2 diabetes: a 2-year follow-up. Diabetes Care 2001;24:995-1000.

25. Guyatt G, Oxman AD, Akl EA, et al. Grade guidelines: 1. Introduction-GRADE evidence profiles and summary of findings tables. J Clin Epidemiol 2011;64:383-94.

26. Tufanaru C, Munn Z, Stephenson M, et al. Fixed or random effects meta-analysis? Common methodological issues in systematic reviews of effectiveness. Int J Evid Based Healthc 2015;13:196-207.

27. Wang $\mathrm{R}$, Lagakos $\mathrm{SW}$, Ware $\mathrm{JH}$, et al. Statistics in medicine reporting of subgroup analyses in clinical trials. N Engl J Med 2007;357:2189-94.

28. Fitzgibbon ML, Stolley MR, Schiffer L, et al. Obesity reduction black intervention trial (orbit): 18-month results. Obesity 2010;18:2317-25.

29. Wing RR, Lang W, Wadden TA, et al. Benefits of modest weight loss in improving cardiovascular risk factors in overweight and obese individuals with type 2 diabetes. Diabetes Care 2011;34:1481-6.

30. Whelton PK, Appel LJ, Espeland MA, et al. Sodium reduction and weight loss in the treatment of hypertension in older persons: a randomized controlled trial of nonpharmacologic interventions in the elderly (TONE). TONE Collaborative Research Group. JAMA 1998;279:839-46.

31. Knowler WC, Barrett-Connor E, Fowler SE, et al. Reduction in the incidence of type 2 diabetes with lifestyle intervention or metformin. N Engl J Med 2002;346:393-403. 
32. Tapsell LC, Lonergan M, Batterham MJ, et al. Effect of interdisciplinary care on weight loss: a randomised controlled trial. BMJ Open 2017;7:e014533.

33. Jensen MD, Ryan DH, Apovian CM, et al. 2013 AHA/ACC/TOS guideline for the management of overweight and obesity in adults: a report of the American College of Cardiology/American heart association Task force on practice guidelines and the obesity Society. J Am Coll Cardiol 2014;63:2985-3023.

34. Kritchevsky SB, Beavers KM, Miller ME, et al. Intentional weight loss and all-cause mortality: a meta-analysis of randomized clinical trials. PLoS One 2015;10:e0121993.

35. Ma C, Avenell A, Bolland M, et al. Effects of weight loss interventions for adults who are obese on mortality, cardiovascular disease, and cancer: systematic review and meta-analysis. BMJ 2017;359.

36. Shea MK, Nicklas BJ, Houston DK, et al. The effect of intentional weight loss on all-cause mortality in older adults: results of a randomized controlled weight-loss trial. Am J Clin Nutr 2011;94:839-46.

37. Cardoso L, Rodrigues D, Gomes L, et al. Short- and long-term mortality after bariatric surgery: a systematic review and metaanalysis. Diabetes Obes Metab 2017;19:1223-32.

38. Golzarand M, Toolabi K, Farid R. The bariatric surgery and weight losing: a meta-analysis in the long- and very long-term effects of laparoscopic adjustable gastric banding, laparoscopic Roux-en-Y gastric bypass and laparoscopic sleeve gastrectomy on weight loss in adults. Surg Endosc 2017;31:4331-45.

39. Williamson DA, Bray GA, Ryan DH. Is $5 \%$ weight loss a satisfactory criterion to define clinically significant weight loss? Obesity 2015;23:2319-20.

40. Gillett M, Royle P, Snaith A, et al. Non-Pharmacological interventions to reduce the risk of diabetes in people with impaired glucose regulation: a systematic review and economic evaluation. Health Technol Assess 2012;16:1-236.

41. Daumit GL, Dickerson FB, Wang N-Y, et al. A behavioral weight-loss intervention in persons with serious mental illness. $N$ Engl $J$ Med 2013;368:1594-602.

42. Shea MK, Houston DK, Nicklas BJ, et al. The effect of randomization to weight loss on total mortality in older overweight and obese adults: the adapt study. J Gerontol A Biol Sci Med Sci 2010;65A:519-25.

43. Rejeski WJ, Brubaker PH, Goff DC, et al. Translating weight loss and physical activity programs into the community to preserve mobility in older, obese adults in poor cardiovascular health. Arch Intern Med 2011;171:880-6.

44. Penn L, White M, Oldroyd J, et al. Prevention of type 2 diabetes in adults with impaired glucose tolerance: the European diabetes prevention RCT in Newcastle upon Tyne, UK. BMC Public Health 2009;9:342

45. Ma J, Yank V, Xiao L, et al. Translating the diabetes prevention program lifestyle intervention for weight loss into primary care. JAMA Intern Med 2013;173:113-21.

46. Messier SP, Mihalko SL, Legault C, et al. Effects of intensive diet and exercise on knee joint loads, inflammation, and clinical outcomes among overweight and obese adults with knee osteoarthritis. JAMA 2013:310:1263-73.

47. Ramachandran A, Snehalatha C, Mary S, et al. The Indian diabetes prevention programme shows that lifestyle modification and metformin prevent type 2 diabetes in Asian Indian subjects with impaired glucose tolerance (IDPP-1). Diabetologia 2006;49:289-97.

48. Goodwin PJ, Segal RJ, Vallis M, et al. Randomized trial of a telephone-based weight loss intervention in postmenopausal women with breast cancer receiving letrozole: the LISA trial. J Clin Oncol 2014;32:2231-9.

49. Foster-Schubert KE, Alfano CM, Duggan CR, et al. Effect of diet and exercise, alone or combined, on weight and body composition in overweight-to-obese postmenopausal women. Obesity 2012;20:1628-38.

50. Patrick K, Calfas KJ, Norman GJ, et al. Outcomes of a 12-month web-based intervention for overweight and obese men. Ann Behav Med 2011;42:391-401

51. Bhopal RS, Douglas A, Wallia S, et al. Effect of a lifestyle intervention on weight change in South Asian individuals in the UK at high risk of type 2 diabetes: a family-cluster randomised controlled trial. Lancet Diabetes Endocrinol 2014;2:218-27.

52. Roumen C, Feskens EJM, Corpeleijn E, et al. Predictors of lifestyle intervention outcome and dropout: the slim study. Eur J Clin Nutr 2011;65:1141-7.

53. Green CA, Yarborough BJH, Leo MC, et al. The STRIDE weight loss and lifestyle intervention for individuals taking antipsychotic medications: a randomized trial. Am J Psychiatry 2015;172:71-81.

54. Eriksson MK, Franks PW, Eliasson M. A 3-year randomized trial of lifestyle intervention for cardiovascular risk reduction in the primary care setting: the Swedish Björknäs study. PLoS One 2009;4:e5195.

55. Davis BR, Blaufox MD, Oberman A, et al. Reduction in long-term antihypertensive medication requirements. Effects of weight reduction by dietary intervention in overweight persons with mild hypertension. Arch Intern Med 1993;153:1773-82.

56. Whelton PK, Appel L, Charleston J, et al. The effects of nonpharmacologic interventions on blood pressure of persons with high normal levels. Results of the trials of hypertension prevention, phase I. JAMA 1992;267:1213-20.

57. Whelton PK, Kumanyika SK, Cook NR, et al. Efficacy of nonpharmacologic interventions in adults with high-normal blood pressure: results from phase 1 of the trials of hypertension prevention. trials of hypertension prevention Collaborative Research Group. Am J Clin Nutr 1997;65(2):652S-60.

58. Villareal DT, Chode S, Parimi N, et al. Weight loss, exercise, or both and physical function in obese older adults. $N$ Engl $J$ Med 2011;364:1218-29.

59. Gabriel KK, Conroy MB, Schmid KK, et al. The impact of weight and fat mass loss and increased physical activity on physical function in overweight, postmenopausal women: results from the women on the move through activity and nutrition study. Menopause 2011:18:759-65. 